\title{
MAPEAMENTO DAS UNIDADES DE RELEVO NA BACIA HIDROGRÁFICA DO RIO JAGUARIZINHO
}

\author{
Vinicius Silveira dos Santos ${ }^{(a)}$, Luís Eduardo de Souza Robaina ${ }^{(b)}$, Igor da Silva Knierin ${ }^{(\mathrm{c})}$, Eloisa \\ Penna da Rosa ${ }^{(d)}$ \\ (a) Mestrando em Geografia, Universidade Federal de Santa Maria, viniciusgeografia93@gmail.com \\ (b) Professor Doutor do Curso de Geografia, Universidade Federal de Santa Maria, lesrobaina@yahoo.com.br \\ (c) Mestrando em Geografia, Universidade Federal de Santa Maria, igorknierin@gmail.com \\ (d) Mestranda em Geografia, Universidade Federal de Santa Maria, eloisapenna@ hotmail.com
}

\section{EIXO: SISTEMA GEOMORFOLÓGICO: ESTRUTURA, DINÂMICA E PROCESSOS}

\begin{abstract}
Resumo
Analisar as características físicas do relevo, superfície onde ocorre a interação homem e natureza, e entende-las, contribui na abordagem dos estudos ambientais. O objetivo do trabalho foi estabelecer a definição das Unidades de Relevo da Bacia Hidrográfica do Rio Jaguari - Mirim, na região Oeste do Estado do Rio Grande do Sul, a partir de um banco de dados cartográfico georreferenciado. Utilizouse como base as Cartas Topográficas em escala 1:50.000, e os dados de radar SRTM. Definiu-se cinco unidades de relevo sendo: Unidade Áreas Planas, nas baixas altitudes e declividades menores que 2\%; Unidade Associação de Morros e Morrotes, segunda maior unidade, associada ao rebordo do planalto; Unidade Colinas de Altitude, maior unidade com $73,03 \%$ da área total; Unidade Colinas Suavemente Onduladas, associada aos declives entre $2-5 \%$, próxima a foz do Rio Jaguari-Mirim; Unidade Morros e Morrotes Isolados, representa as áreas com declives maiores que $15 \%$ altitudes maiores que 120 metros. Entende-se que compreender como o relevo se distribui, é imprescindível para as questões voltadas para uma gestão ambiental.
\end{abstract}

Palavras chave: Bacia Hidrográfica. Rio Jaguari - Mirim. Unidades de Relevo.

\section{Introdução}

A apropriação dos recursos naturais pelo homem, vem crescendo consideravelmente, atendendo a uma grande demanda econômica e social, sem se ter a preocupação pela preservação e manutenção das formas naturais do espaço geográfico.

Dessa forma, o espaço geográfico apresenta-se em constante transformação, sendo esses processos modeladores oriundos de ações naturais (fatores endógenos e exógenos) ou oriundos de ações antrópica, tendo o homem o papel de principal acelerador dos processos alteradores da paisagem.

O relevo, superfície em que ocorre a interação entre o homem e a natureza, apresenta-se como temática fundamental para estudos ambientais, sendo o elemento caracterizador da paisagem.

Alguns dos primeiros estudos que analisaram e classificaram o relevo a partir de parâmetros morfométricos (baseando-se no comportamento de fluxos superficiais em vertentes) foram desenvolvidos 
por Troeh (1965) e Huggett (1975). No Brasil destacam-se como os primeiros trabalhos, os desenvolvidos pelo projeto RadamBrasil (1986).

Na região Oeste do Rio Grande do Sul, destacam-se trabalhos desenvolvidos por De Nardin et al (2005), Trentin et al (2012) e Sccoti et al (2013) utilizando a proposta de definição de unidades de relevo, a partir de parâmetros altimétricos, correlacionando com parâmetros de declividade e as formas das encostas.

Os métodos de classificação atuais possibilitam a subdivisão das formas em elementos do relevo, que são um conjunto de parcelas de um tipo de relevo relativamente homogênea em relação a curvaturas de perfil e de plano, inclinação, orientação e posicionamento na paisagem (MACMILLAN E SHARY, 2009).

As bacias hidrográficas apresentam-se como a materialização de diferentes elementos integradores do meio físico, resultado dos processos modeladores atuantes no relevo, caracterizando um sistema exposto a intervenções. Dessa forma, representam unidades fundamentais para os estudos ambientais.

Nas análises ambientais a utilização de um banco de dados cartográfico manipulados em SIG (Sistemas de Informação Geográficas) permite a obtenção das características do relevo e o processamento de modo rápido e eficiente. A parametrização da morfologia do relevo por meio de SIG é o processo de extração de atributos quantitativos da topografia.

Desta forma, Muñoz (2009), descreve de forma quantitativa as formas da superfície da Terra por meio de equações aplicadas a modelos numéricos de representação altimétrica.

Frente a isso, o presente trabalho traz como proposta a definição das Unidades de Relevo da Bacia Hidrográfica do Rio Jaguari - Mirim (BHRJM), situada na região oeste do Estado do Rio Grande do Sul (Figura 1), a partir de interpolação e interpretação em ambiente de SIG, de um banco de dados georreferenciado. 

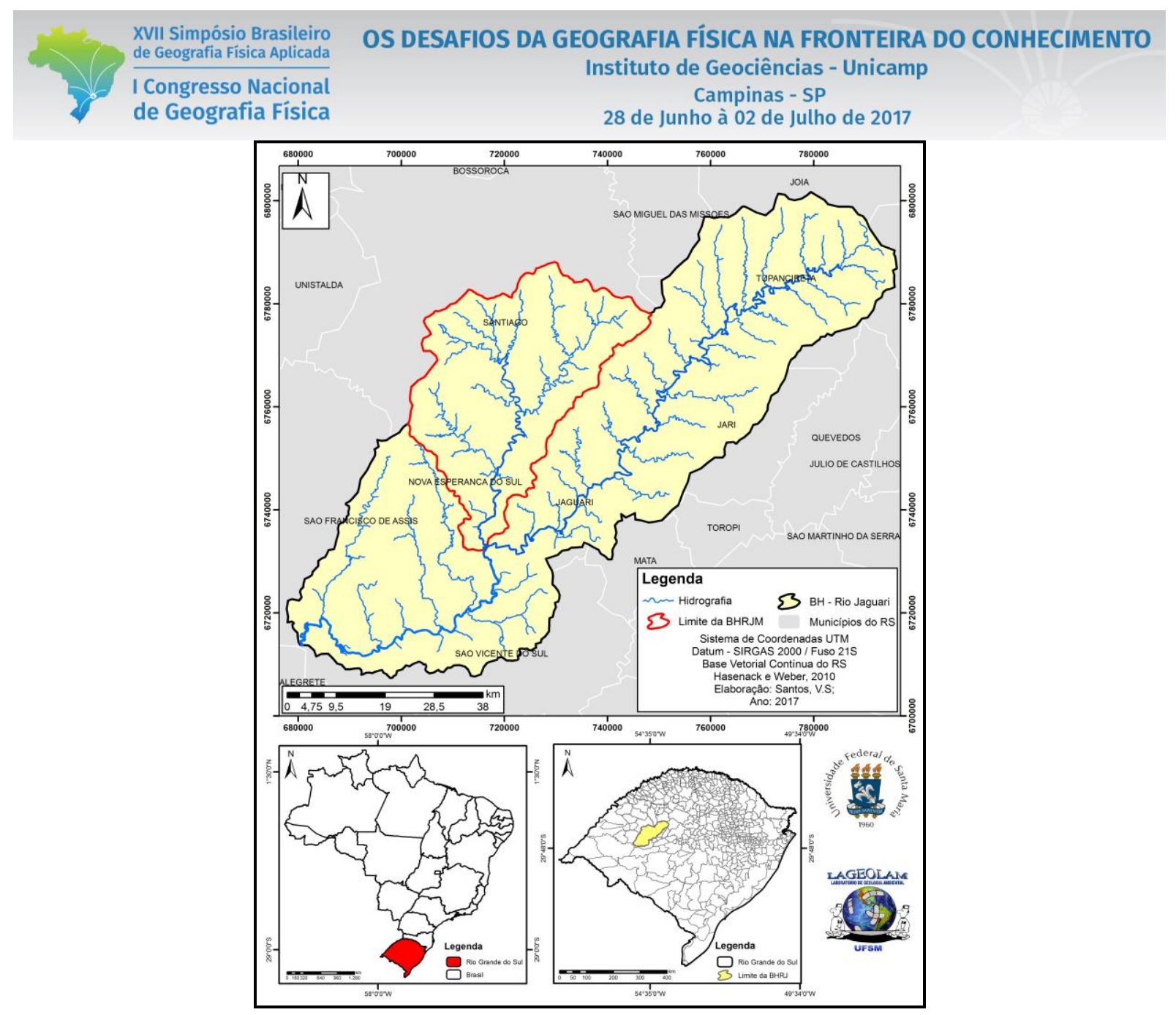

Figura 1 - Mapa de localização da BHRJM.

\section{Meterial e Método}

Para o desenvolvimento do trabalho, foram utilizadas bases cartográficas em formato Vetorial e formato Raster, sendo que o banco de dados no formato vetorial está em escala 1: 50.000, disponível pelo trabalho de Hasenack e Weber (2010). As informações extraídas da base cartográfica vetorial do Estado do Rio Grande do Sul foram: hidrografia e curvas de nível (para a delimitação da área da bacia).

A base cartográfica no formato Raster, possibilitou a análise dos elementos fisiográficos do relevo (hipsometria, declividade) a partir das informações altimétricas obtidas na imagem SRTM (Shuttle Radar Topography Misson) com resolução de 30 metros, sendo estes dados processados na interface do software ArcGis versão 10.1.

O mapa hipsométrico e o mapa de declividade, são produtos gerados a partir de Modelos Digital de Elevação (MDE), que representam uma grandeza que varia continuadamente no espaço. Na manipulação do MDE, utilizou-se a ferramenta "Fill", que tem a finalidade de corrigir os pixels nulos, adquirindo a média altimétrica dos pixels vizinhos. 


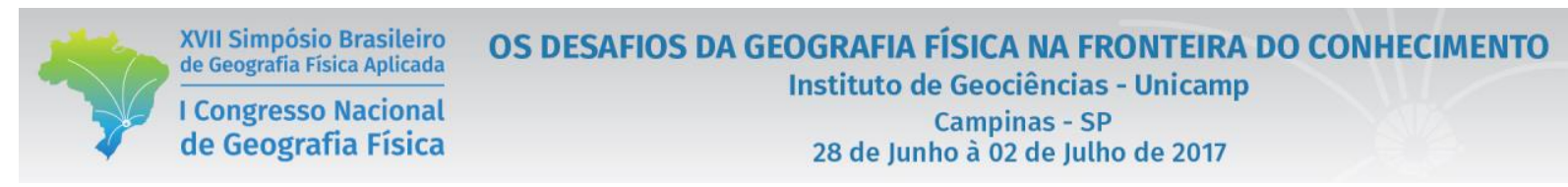

Os dados referentes à hipsometria, foram gerados pela ferramenta ArcToolbox "Topo to Raster", resultado das interpolações referentes aos parâmetros altimétricos. As classes hipsométricas foram definidas através de quebras no relevo e arredondamentos matemáticos: São elas: < 100m; 100-200m; 200-300m; 300400m; > 400m.

Os parâmetros de declividade, foram gerados pela ferramenta ArcToolbox "Slope", a partir das informações do MNT, utilizando como parâmetros para a definição das classes de declividade, a classificação proposta pelo Instituto de Pesquisas Tecnológicas (IPT), sendo elas: $<2 \%$; 2-5\%; 5-15\%; e $>15 \%$. Com esta classificação, é possivel caracterizar a atuação dos processos erosivos relacioados a declividade (Tabela I).

Tabela I- Caracterização dos processos erosivos em relação à declividade.

\begin{tabular}{c|l}
\hline Declividade & \multicolumn{1}{c}{ Influência nos processos erosivos } \\
\hline$<2 \%$ & $\begin{array}{l}\text { Áreas planas em geral associadas às drenagens e sujeitas a ocorrência de inundações } \\
\text { e os principais processos estão ligados a deposição de sedimentos. }\end{array}$ \\
\hline $2-5 \%$ & $\begin{array}{l}\text { Áreas com baixa declividade, porém alguns processos erosivos se tornam } \\
\text { significativos. }\end{array}$ \\
\hline $5-15 \%$ & Áreas com declividades consideráveis, com a atuação de processos erosivos. \\
\hline $15 \%$ & $\begin{array}{l}\text { Áreas com o limite máximo para o emprego da mecanização da agricultura, e } \\
\text { também delimita áreas propicias a ocorrência de processos de movimento de massa e } \\
\text { escorregamentos. }\end{array}$ \\
\hline
\end{tabular}

Org: Os autores, 2017.

As formas do relevo são indicadas pela quantificação da amplitude e da declividade das encostas, baseando-se no método de classificação adotado por De Nardin (2005), em sua pesquisa. O método pode ser representado pela Tabela II:

Tabela II - Classificação dos tipos de relevo.

\begin{tabular}{ccc}
\hline Amplitude altimétrica & Declividade & Unidade de Relevo \\
\hline \multirow{3}{*}{$<100$ metros } & $<2 \%$ & Áreas Planas \\
\cline { 2 - 3 } & $2-5 \%$ & Colinas Suavemente Onduladas \\
\cline { 2 - 3 } & $5-15 \%$ & Colinas de Altitude \\
\hline >100 metros & $>15 \%$ & Morrotes Isolados \\
\hline
\end{tabular}

Fonte: Adaptado, De Nardin, 2005.

Desta forma, realizou-se a vetorização das Unidades de Relevo, sendo possível posteriormente a correlação das informações visuais (mapa temático) com os dados quantitativos disponíveis pelo 
histograma de frequência, e caracterizar as Unidades de Relevo na BHRJM. Para uma melhor caraterização das Unidades de Relevo, gerou-se também 4 (quatro) perfis topográficos.

\section{Resultados e Discussões}

A BHRJ apresenta uma área aproximada de $1.323,22 \mathrm{~km}^{2}$, sendo que o canal principal apresenta hierarquia máxima de $5^{\mathrm{a}}$ ordem, conforme a classificação proposta por Strahler (1952). O Rio Jaguari Mirim é um dos principais afluentes do Rio Jaguari (BHRJ), sendo este um dos principais tributários à margem direita.

A análise da hipsometria apresenta as diferentes altitudes distribuídas na área de estudo, comparadas ao nível do mar. A bacia hidrográfica caracteriza-se com uma amplitude altimétrica de 369 metros, sendo a menor cota de 92 metros, localizada próxima à foz do rio, e a maior cota é de 461 metros, localizada ao norte e noroeste da bacia hidrográfica.

As altitudes inferiores a $100 \mathrm{~m}(<100 \mathrm{~m})$, ocupam $0,93 \%$ da área total, sendo esta classe pouco representativo, com baixas altitudes, caracterizando o relevo em porções planas, definindo a forma de escoamento no canal principal. As altitudes com valores entre 100-200m distribuem-se por 7,63\% da área total da BHRJM, ocupando uma porção do terreno próximo as áreas planas.

Altitudes entre 200 à 300m, ocupam 25,48\% da área total, caracterizam claramente a região de Rebordo do Planalto, com declives acentuados, que acabam influenciando nas formas das vertentes. Predominam na BHRJM, altitudes que variam de 300 à 400m, ocupando $61,01 \%$ da área total da bacia hidrográfica, caracterizando a região geomorfológica do Planalto. Altitudes superiores a 400m, ocupam 4,93\% da área total, distribuem-se ao norte e noroeste da bacia hidrográfica, estando a nascente do canal principal situado em altitudes de 433m. Na Figura 2 é possível observar a distribuição espacial das classes hipsométricas na BHRJM. 

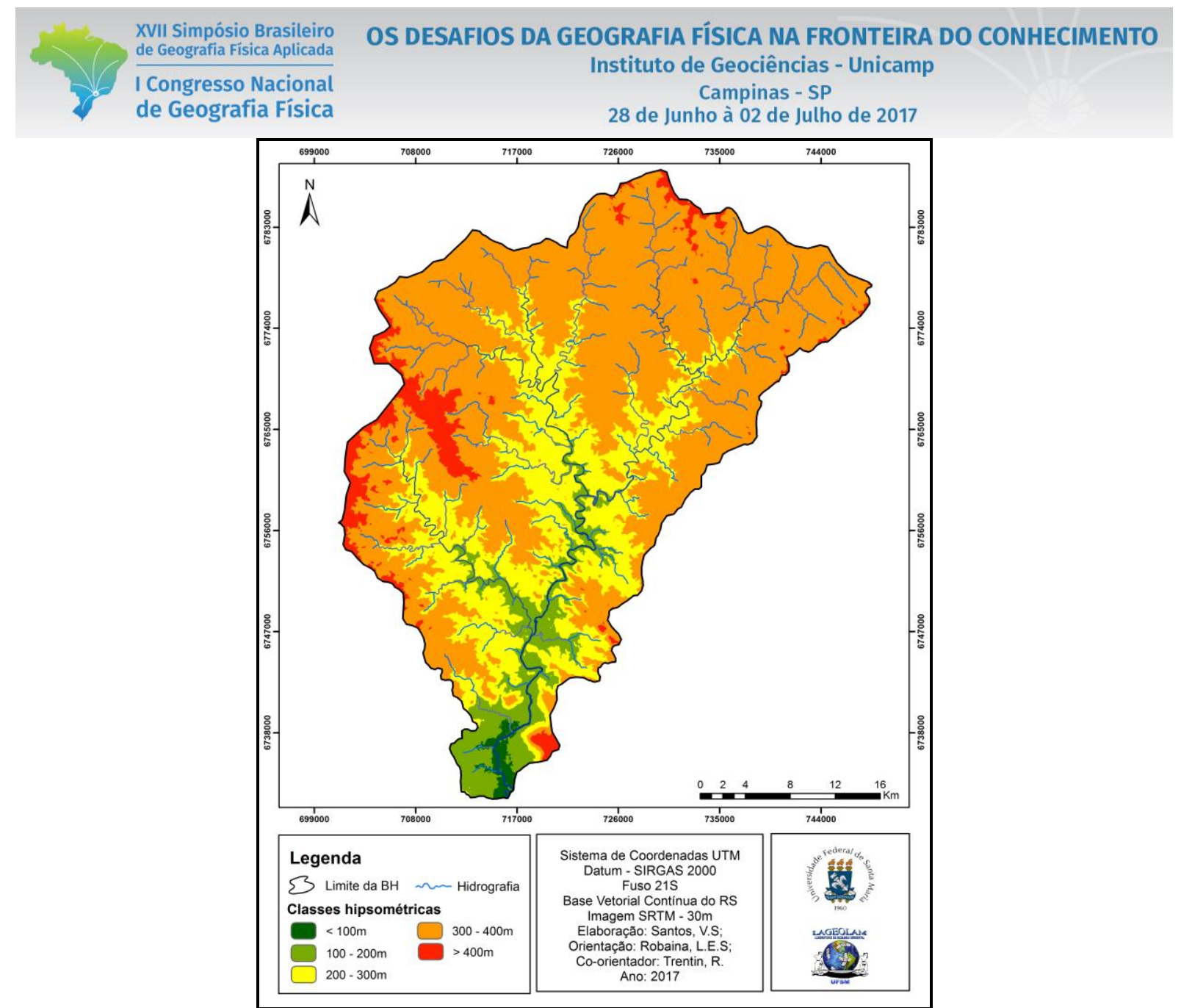

Figura 2 - Mapa hipsométrico da BHRJM.

A declividade das encostas, influencia diversos fatores que contribuem nos processos alteradores nas formas das vertentes, como os movimentos de massa, e processos erosivos, além de interferirem nos processos de uso e ocupação dos solos.

As declividades menores que $2 \%\left(115,53 \mathrm{~km}^{2}\right)$, caracterizam o relevo em Áreas Planas, localizados junto a foz do canal principal. Nesses declives, a deposição de sedimentos transportados pelos canais é considerável, surgindo bancos de areia. Além disso, nessa região é propicia a cultura de plantações de arroz.

Em sequência, os declives entre $2-5 \%\left(283,21 \mathrm{~km}^{2}\right)$ caracterizam o relevo em Colinas Suaves associadas a áreas do baixo curso do rio principal, na Depressão Periférica.

Os declives entre 5 - 15\% predominam-se na bacia hidrográfica, com uma área de $696,30 \mathrm{~km}^{2}$. Essas declividades são visualizadas no alto curso da bacia, caracterizando o relevo em Colinas Fortemente Onduladas ou de Altitudes no Planalto Meridional.

Por fim, os declives maiores que 15\% (227,46 km²), caracterizam o relevo em Associações de Morros e Morrotes. Esses declives representam o Rebordo do Planalto, região de transição entre o Planalto 
XVII Simpósio Brasileiro de Geografia Fisica Aplicada

I Congresso Nacional de Geografia Física
OS DESAFIOS DA GEOGRAFIA FÍSICA NA FRONTEIRA DO CONHECIMENTO

Instituto de Geociências - Unicamp

Campinas - SP

28 de Junho à 02 de Julho de 2017

Meridional e a Depressão Periférica. Além disso, há presença de Morrotes Isolados em regiões planas, representado por esta classe de declividade. Na Figura 3 é possível observar a distribuição espacial das classes de declividade.

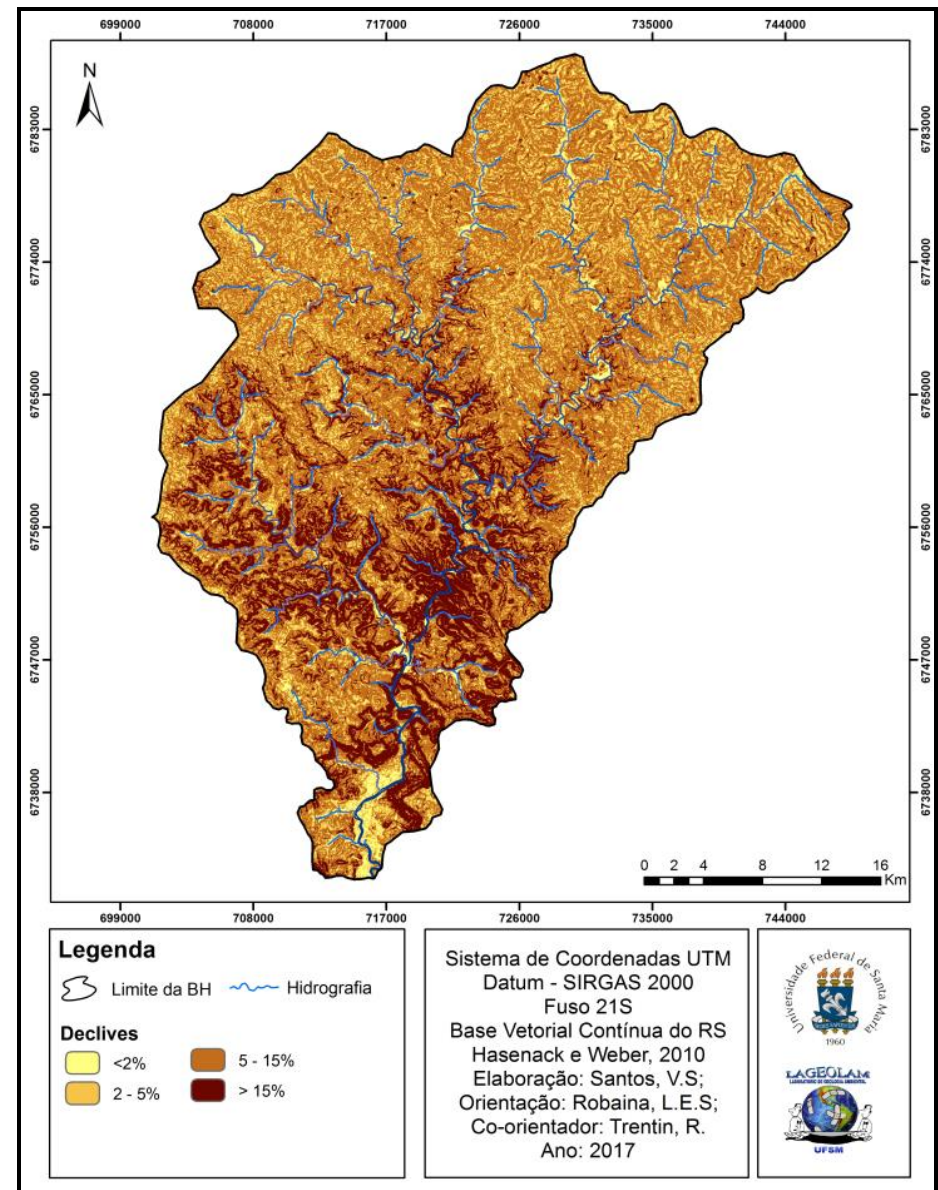

Figura 3 - Mapa de declividade da BHRJM.

\section{Unidades de Relevo}

Na interpolação dos dados altimétricos, para a definição das Unidades de Relevo, consegue-se visualizar a distribuição das mesmas (Figura 4), dentro da área de estudo.

\section{Unidade Áreas Planas}

A unidade Áreas Planas que está exemplificada com o perfil (A-A') (Figura 5) apresenta-se com uma área de $36,11 \mathrm{~km}^{2}$, representando $2,72 \%$ da área total. A unidade está associada à altitude baixas e declives 


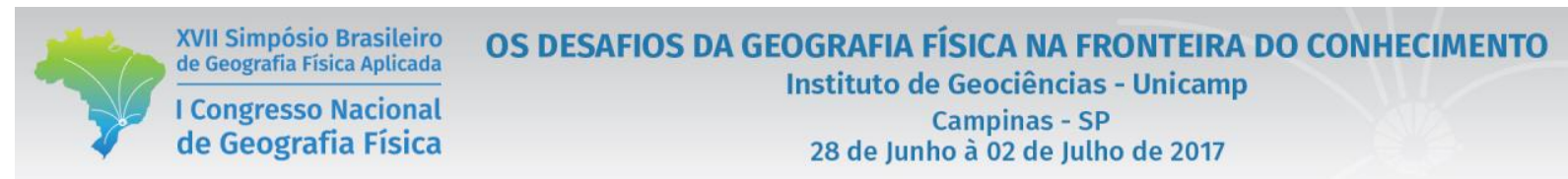

menores que $2 \%$, situada na região sul da bacia hidrográfica. Em regiões com essas características, propicia a deposição de sedimentos ao longo do canal fluvial e na redução da velocidade do fluxo da água. Esta unidade, caracteriza-se com baixa variação altimétrica, ocorrendo deposição no canal principal, e inundações na várzea, com altitudes que variam de $90 \mathrm{~m}$ à $110 \mathrm{~m}$.

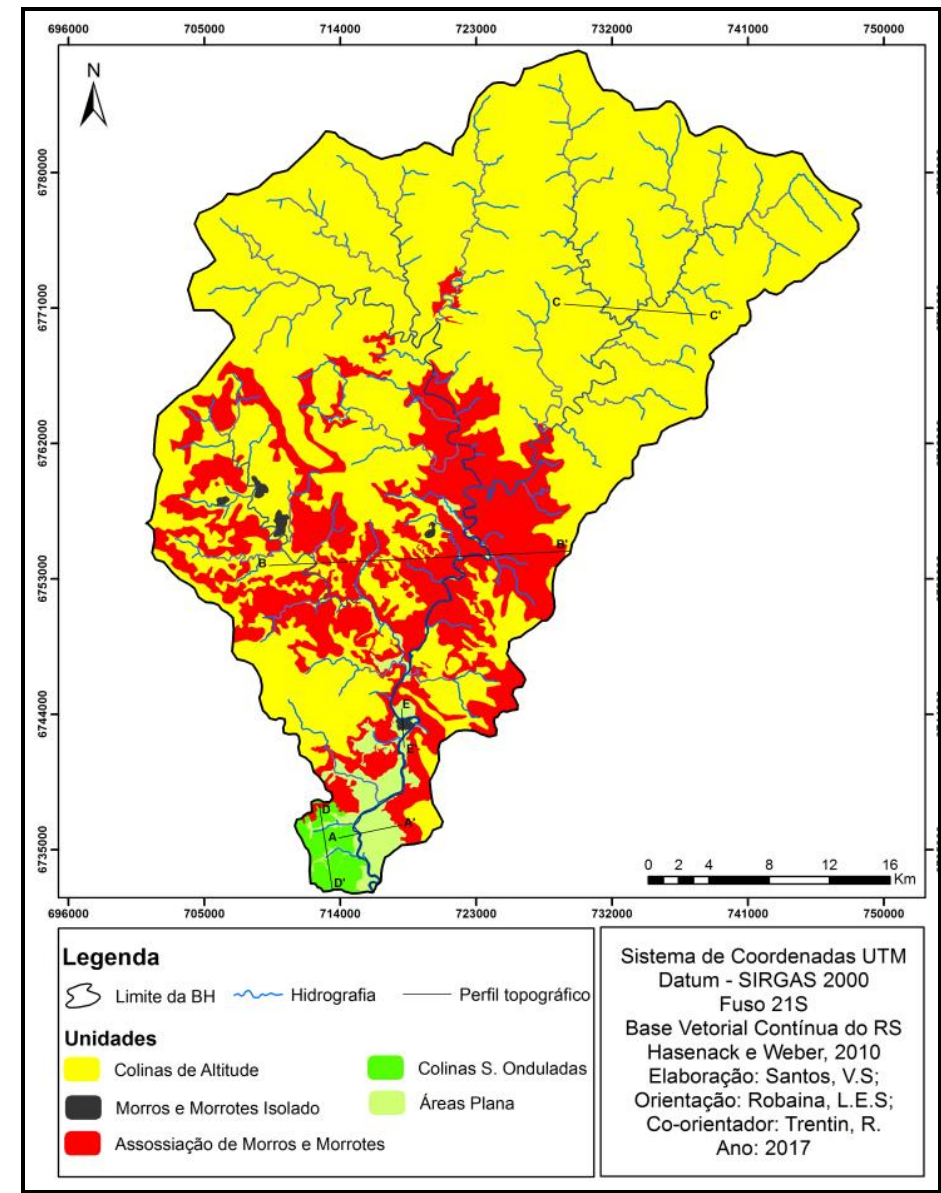

Figura 4- Mapa de Unidades de Relevo da BHRJM.

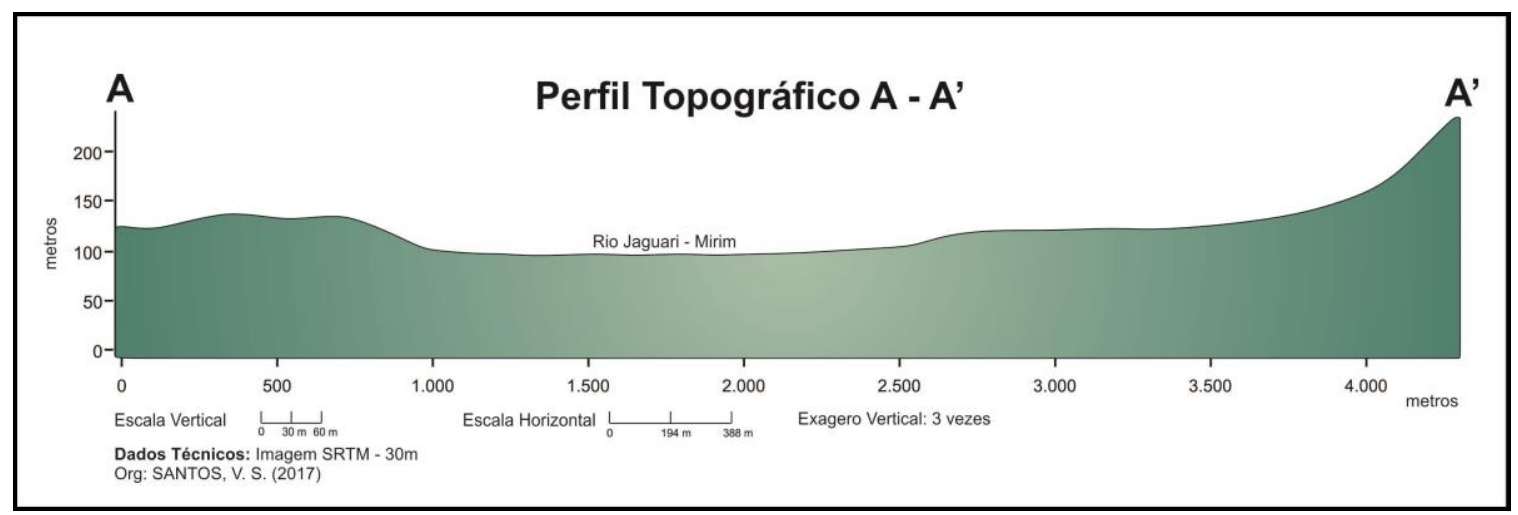

Figura 5 - Perfil topográfico A-A' na BHRJM. 


\section{Unidade Associação de Morros e Morrotes}

A unidade Associação de Morros e Morrotes apresentam-se como a segunda maior unidade de relevo na bacia hidrográfica. Com uma área de $301,72 \mathrm{~km}^{2}$, a unidade representa $22,80 \%$ da área total. A unidade está associada ao rebordo do planalto, com altitudes que variam de $160 \mathrm{~m}$ à superiores de $400 \mathrm{~m}$, com declives maiores que $15 \%$, sendo uma região de transição entre o Planalto Meridional e a Depressão Periférica.

O perfil topográfico B-B' (Figura 6), caracteriza a transição geomorfológica entre o Planalto Meridional e a Depressão Periférica. Os canais de drenagem apresentam elevadas variações altimétrica, que acarreta na intensidade do escoamento da água, influenciando nos processos erosivos.

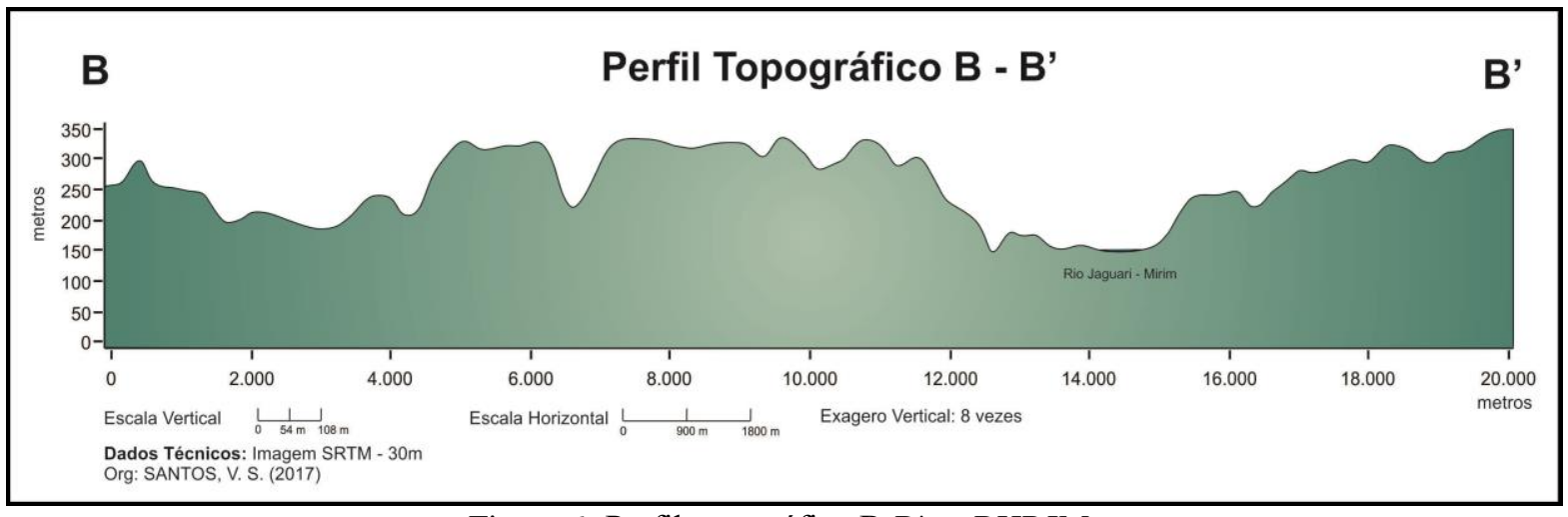

Figura 6- Perfil topográfico B-B' na BHRJM.

\section{Unidade Colinas de Altitude}

A unidade Colinas de Altitudes apresenta área de $966,42 \mathrm{~km}^{2}$, representando 73,03\% da área total. Esta unidade distribui-se predominantemente ao norte da bacia, além de estender-se na porção oeste e leste da área de estudo. A unidade apresenta amplitude altimétrica média de $40 \mathrm{~m}$, sendo considerado Colinas de Altitude, com altimetria superior a 300m, e amplitude inferior à $100 \mathrm{~m}$, e declividades variando entre 5 $15 \%$.

Estes declives são visualizados no alto curso da bacia, condicionando a atividades agrícolas, por exemplo, muito intensa nas regiões do Planalto Meridional. As formas de vertentes Côncava - Divergente distribuem -se pela unidade, caracterizando no fluxo d'água acumulado, sendo influenciado pela forma da encosta. 
O perfil topográfico C-C"' (Figura 7), apresenta uma visualização das encostas nesta unidade. Caracterizase por conter altitudes que variam de $280 \mathrm{~m}$ (A) na porção oeste e nordeste, à $350 \mathrm{~m}$ de altitude próximo ao canal fluvial. O relevo ondulado, caracteriza o canal de drenagem encaixado, estando estes próximos a cabeceiras de drenagem, levando à um fluxo de água rápido.

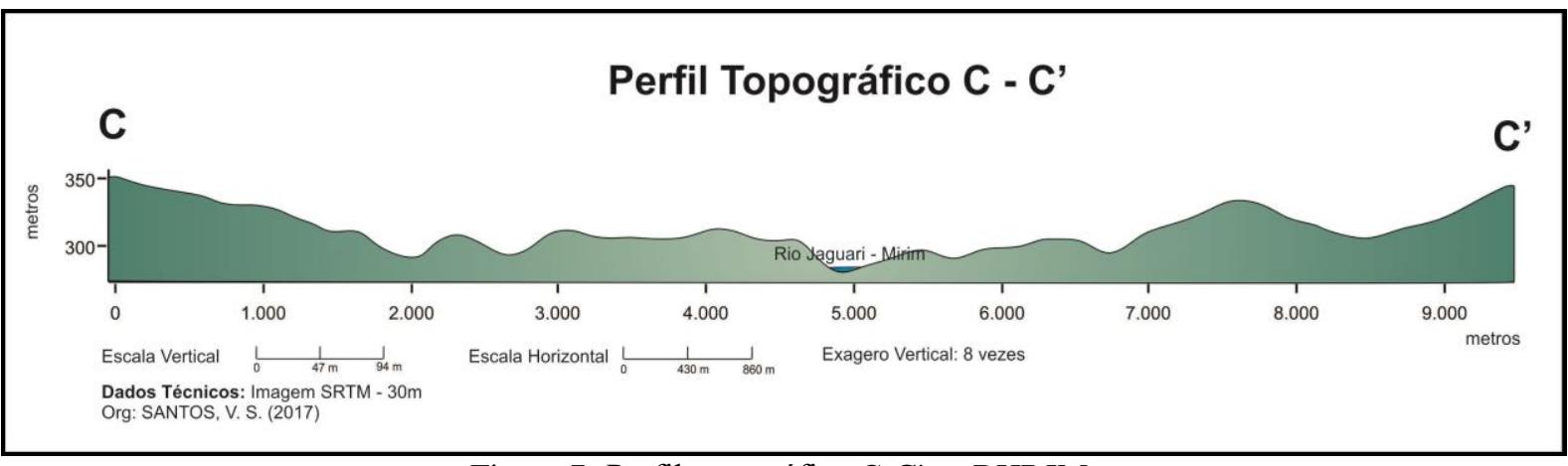

Figura 7- Perfil topográfico C-C' na BHRJM.

\section{Unidade Colinas Suavemente Onduladas}

A unidade Colinas Suavemente Onduladas, apresenta-se com uma área de 14,81 km², representando $1,11 \%$ da área total. A unidade está associada aos declives entre $2-5 \%$, próxima a foz do Rio JaguariMirim, assossiadas as áreas planas.

Esta unidade caracteriza-se por amplitudes altimétricas menores que $100 \mathrm{~m}$, que marcam no relevo porções onduladas, próximas à região do Rebordo e ao canal principal. O perfil D-D' topográfico (Figura 8), apresenta uma visão das características da variação altimétrica e da amplitude de 40m desta unidade. Nessas condições, devido à pouca declividade, os sedimentos trazidos do Planalto Meridional e do Rebordo do Planalto, depositam-se próximo as margens aos canais de drenagem, influenciando na formação de bancos de areia isolados e consequentemente diminuindo a velocidade de escoamento da água. 


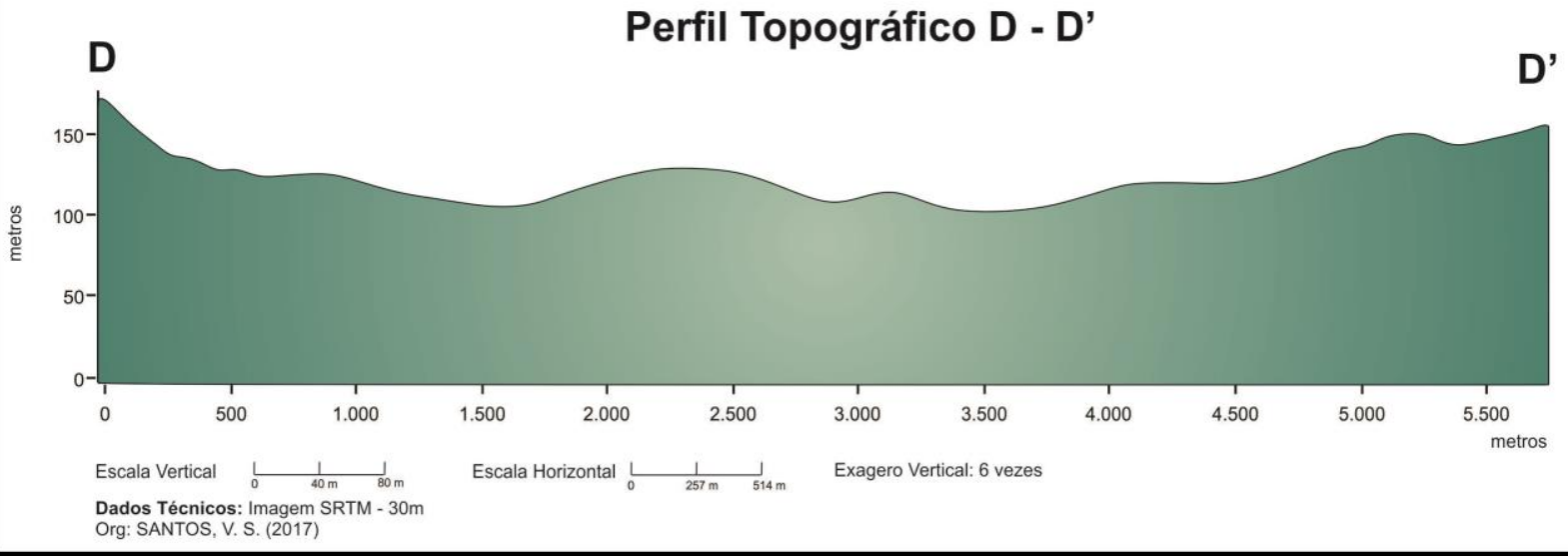

Figura 8- Perfil topográfico D-D' na BHRJM.

Org: Os autores, 2016.

\section{Unidade Morros e Morrotes Isolados}

A unidade de Morros e Morrotes Isolados apresenta uma área de 4,16 km², representando cerca de 0,31\% dá área total da bacia hidrográfica. A unidade representa Morros e Morrotes, com declives maiores que 15\% e com cotas altimétricas maiores que 120 metros. O perfil topográfico C-C' (Figura 9), caracteriza um Morrote próximo ao canal principal à margem esquerda, com amplitude aproximada de 80 metros. $\mathrm{O}$ Morrote em análise, situa-se em região plana e próxima às Colinas Suavemente Onduladas, o que influencia no carregamento de matérias para o rio, e caracteriza o tipo de vegetação existente na área da BHRJM.

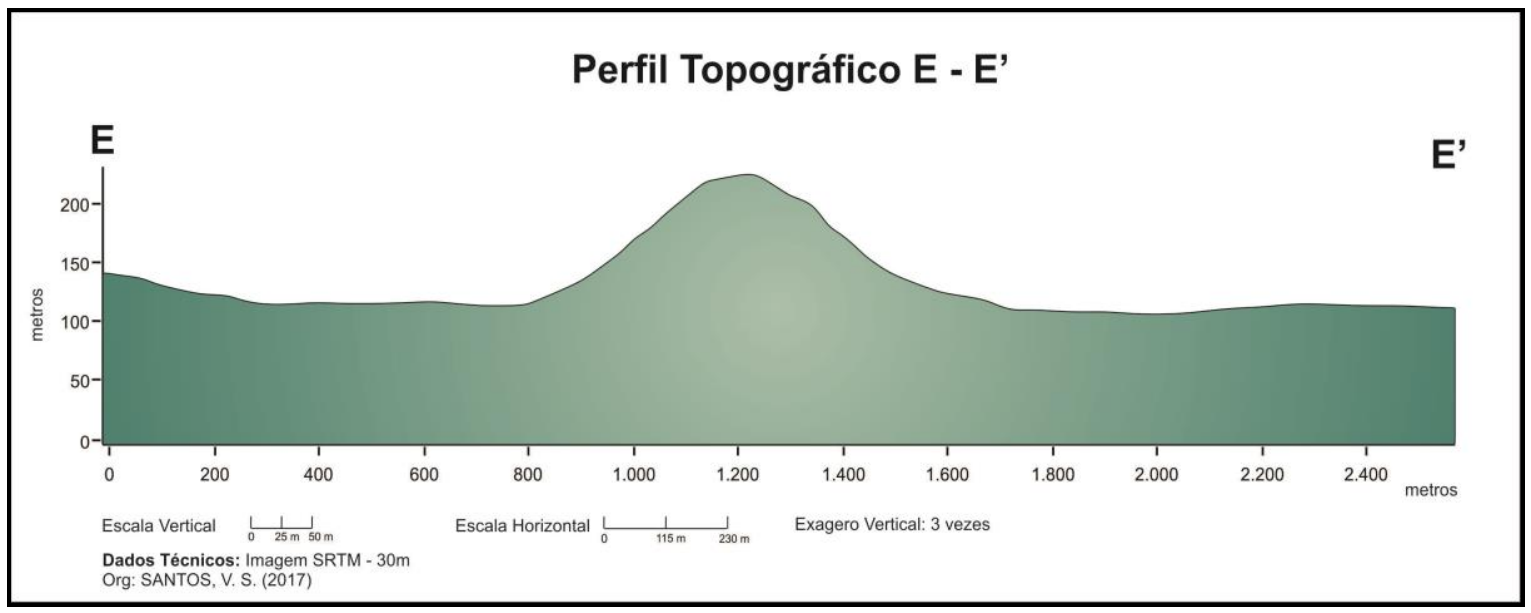

Figura 9- Perfil topográfico E-E’ na BHRJ. 


\section{Considerações Finais}

A BHRJ distribui-se por vários municípios da região oeste, apresentando em diversas áreas, diferentes formas do relevo, que acabam influenciando no modo de uso e ocupação do solo.

A partir da metodologia aplicada, foi possível delimitar cinco unidades de relevo, sendo elas Unidade Áreas Planas, nas baixas altitudes e declividades menores que 2\%; Unidade Associação de Morros e Morrotes que é a segunda maior unidade da bacia, associada ao rebordo do planalto; Unidade Colinas de Altitude, maior unidade da bacia com73,03\% da área total; Unidade Colinas Suavemente Onduladas que está associada aos declives entre $2-5 \%$, próxima a foz do Rio Jaguari-Mirim; Unidade Morros e Morrotes Isolados representa as áreas com declives maiores que 15\% e com cotas altimétricas maiores que 120 metros.

Entender os processos de transformação da paisagem, correlacionando as formas de relevo com um levantamento cartográfico, contribui para o planejamento e ordenamento do espaço natural, de modo equilibrado.

\section{Referências Blibiográfica}

BOTELHO, R. G. M. Planejamento Ambiental em Microbacia Hidrográfica. In: Erosão e conservação dos solos: conceitos, temas e aplicações/ Antônio José Teixeira Guerra, Antônio Soares da Silva, Rosângela Garrido Machado Botelho (organizadores) - Rio de Janeiro: Bertrand Brasil, 1999.

CHRISTOFOLETTI, A. Geomorfologia. 2ª ed. São Paulo: Edgard Blücher, 1980.

DE NARDIN, D; ROBAINA, L.E.S. Mapeamento de Unidades de Relevo no Oeste do RS: O caso da Bacia Hidrográfica do Arroio Miracatú. Anais do XI Simpósio Brasileiro de Geografia Física Aplicada - USP, 2005. p3576 -3588 .

HUGGETT, R.J. Soil landscape systems: A model of soil genesis. Geoderma, Amsterdan, v. 13, p. 1-22, 1975.

Instituto de Pesquisas Tecnológicas. Mapeamento Geomorfológico do Estado de São Paulo. São Paulo. Escala 1:500.000, v. 2, 1981. 130p.

MACMILLAN, R. A.; SHARY, P. A., Landforms and landform elements in geomorphometry. In: HENGL, T. e REUTER, H. I. (eds), Geomorphometry-Concepts, Software, Applications. Developments in Soil Science, vol. 33, Elsevier, Amsterdam, 2009. Pag. 227-254. 
MUÑOZ, V. A. Análise geomorfométrica de dados SRTM aplicada ao estudo das relações solo-relevo. Instituto Nacional de Pesquisas Espaciais, São José dos Campos, 2009. 112p. (INPE-15796-TDI/1531). Dissertação (Mestrado em Sensoriamento Remoto). - Instituto Nacional de Pesquisas Espaciais.

ROSS, J.L.S. O registro cartográfico dos fatos geomórficos e a questão da taxonomia do relevo. Revista do Departamento de Geografia, São Paulo, $n^{\circ}$ 6, 1992. p. 17-29.

SCCOTI, A.A.V; ROBAINA, L.E.S; TRENTIN, R. Compartimentação do relevo no município de Manoel Viana RS. Subdivision of the relief in Manoel Viana municipally - RS. Ciência e Natura, Santa Maria. ISSN: 2179-460X, v. 35 n. 1 jul. 2013, p. 064-070.

TRENTIN, R; SANTOS, L.J.C; ROBAINA, L.E.S. Compartimentação geomorfológica da bacia hidrográfica do rio Itu - Oeste do Rio Grande do Sul - Brasil. Soc. \& Nat., Uberlândia, ano 24 n. 1, 127-142, jan/abr. 2012.

TROEH, F. R. Landform equations fitted to contour maps. American Journal Science, v. 263, p. 616-627, 1965. 